\title{
Ankle Brachial Index Screening for Peripheral Arterial Disease in Asymptomatic Diabetic Patients
}

\author{
Alaa El Deen Dawood, Mahmoud S. El-Desoky, Heba A. El-Malky*, Mai A. Kamel \\ Department of Internal Medicine, Faculty of Medicine, Menoufia University, Egypt. \\ *Corresponding Author: Heba Ashraf El-Malky, Mobile: (+20)01030934655, Email: elmalkyheba549@gmail.com
}

\begin{abstract}
Background: Peripheral arterial disease (PAD) is a common macrovascular complication in diabetic patients related to atherosclerosis. Early diagnosis of PAD by ankle brachial index (ABI) is highly critical as this disease results in significant morbidity and mortality.

Objectives: To screen for PAD in asymptomatic diabetic patients by using $\mathrm{ABI}$, determining its prevalence and associated risk factors.

Patients and Methods: This is a cross-sectional study conducted on 309 diabetic asymptomatic patients in Internal Medicine Department, Menoufia University Hospitals in the period between December 2018 and December 2020. Full history and biochemical profiles were obtained and ABI indices were measured to evaluate for PAD.

Results: The prevalence of PAD in this study was 36.2\%. Advancing age, sedentary life, long duration of diabetes, smoking, poor glycemic control and dyslipidemia were identified as risk factors for PAD ( $\mathrm{p}$ value <0.001) while, hypertension and body mass index were not significant among studied patients ( $\mathrm{p}$ value 0.594 and 0.733 respectively). Conclusion: PAD has a high prevalence in asymptomatic diabetic individuals. It is associated with multiple risk factors such as smoking, dyslipidemia, advancing age, atherosclerosis and prolonged uncontrolled hyperglycemia. Diabetic patients should be routinely examined by ABI to improve the outcome.
\end{abstract}

Keywords: Peripheral Arterial Disease, Diabetes, Ankle brachial index.

\section{INTRODUCTION}

In 2019, an estimated 463 million adults had diabetes all over the world and the number is predicted to be doubled by $2030^{(\mathbf{1})}$. Diabetes mellitus (DM) is a major health problem, which leads to 2.2 million deaths worldwide related to high blood glucose and its associated complications (e.g. heart disease etc.), making it the 8th leading cause of death ${ }^{(2)}$.

Peripheral arterial disease is the narrowing of the visceral arteries and the arteries of the lower limbs due to systemic atherosclerosis (3, 4) leading to limb amputation and death ${ }^{(4)}$. The commonest risk factors to PAD are increasing age, diabetes, obesity, dyslipidemia, hypertension and smoking (5). The American Heart Association estimates that the worldwide prevalence of PAD is 202 million individuals. PAD is a common sequalae in diabetic individuals with 3-4 times higher prevalence than nondiabetic individuals ${ }^{(6)}$ due to several mechanisms related to atherosclerosis as endothelial dysfunction, oxidative stress and production of advanced glycation end- products. Early detection of PAD is critically important for risk factor modification, enhancing of its outcome and minimizing its complications ${ }^{(7)}$.

Ankle brachial index is a simple quick method, which is used for early diagnosis of PAD. The American Heart Association defines the ABI as the ratio of the ankle systolic pressure to the brachial systolic pressure, which is 1-1.4 in normal individuals. $\mathrm{PAD}$ is diagnosed when $\mathrm{ABI}$ is $\leq 0.9$.

The aim of the work was to screen for PAD in asymptomatic diabetic patients by using ABI.

\section{PATIENTS AND METHODS}

This study was designed as a cross-sectional study and was conducted on 309 diabetic patients who did not have any symptoms for PAD and were selected from Outpatient Clinics and Inpatient Wards of Internal Medicine Department in Menoufia University Hospitals from December 2018 to December 2020. Then subjects were subdivided into two groups: Group I included 197 patients without PAD, and Group II included 112 patients with PAD.

Inclusion criteria: Diabetic patients (type 2 DM) without symptoms for PAD and older than 18 years old. Exclusion criteria: Diabetic patients with symptoms for PAD, age less than 18 years old and type1 DM.

\section{All patients were subjected to the following: \\ Full history: A full detailed history is taken including socio-demographic data and diabetic history (duration of DM and anti-diabetic medications), exclusion of symptoms of PAD (e.g., intermittent claudication) and history of risk factors as Smoking and hypertension.}

Complete physical examination: Complete general examination, local examination, anthropometric measures (weight, height, BMI, waist circumference, hip circumference and waist-hip ratio), foot examination (peripheral pulsations, color, temperature, hair, nails and ulcers).

This article is an open access article distributed under the terms and conditions of the Creative Commons Attribution (CC BY-SA) license (http://creativecommons.org/licenses/by/4.0/) 
Measurement of ABI: By using a hand-held Doppler of $8 \mathrm{MHz}$ and sphygmomanometer cuff. The ABI was performed by measuring the systolic blood pressure of both brachial arteries, both dorsalis pedis and posterior tibial arteries in the supine position. The ABI is calculated by dividing the highest systolic blood pressure at the ankle by the highest systolic blood pressures in the arm.

\section{Interpretation of $\mathrm{ABI} \mathbf{}^{(8)}$}

1. ABI value from $1.0-1.4$ is normal.

2. The values above 1.4 suggest a non-compressible calcified vessel as in elderly patients.

3. The value between 0.91-1 is borderline and needs follow up.

4. $\mathrm{ABI} \leq 0.9$ is diagnostic of $\mathrm{PAD}$.

- The values from 0.8-0.9 are mild PAD.

- The values from 0.4-0.79 are moderate PAD.

- The values less than 0.4 suggest severe PAD.

Laboratory investigations including fasting blood glucose, $2 \mathrm{hr}$ post prandial blood glucose, HBA1c, lipid profile, complete blood count (CBC), serum urea, serum creatinine, albumin /creatinine ratio, AST, ALT and serum albumin tests.

Ethical approval and written informed consent:

An approval of the study was obtained from Menoufia University Academic and Ethical Committee. Every patient signed an informed written consent for acceptance of the operation.

\section{Statistics and Analysis}

Statistics were done by using SPSS version 23 software for analysis. Numeric variables were represented as mean \pm standard deviation, while nonnumeric data were presented as frequency and percentage.

Student's t-test is a test of significance used for comparison of quantitative variables between two groups of normally distributed data, while Mann Whitney's test was used for comparison of quantitative variables between two groups of not normally distributed data. Chi-square test $\left(\chi^{2}\right)$ was used to study association between qualitative variables. Correlations between different parameters were determined by bivariate Pearson correlation test. P- value of $\leq 0.05$ was considered statistically significant.

\section{RESULTS}

Table (1): Comparison between studied patients regarding demographic data (no=309)

\begin{tabular}{|c|c|c|c|c|}
\hline & $\begin{array}{l}\text { Group I } \\
\text { No=197 }\end{array}$ & $\begin{array}{c}\text { Group II } \\
\text { No=112 }\end{array}$ & $\begin{array}{c}\text { Test of } \\
\text { significance }\end{array}$ & $P$ value \\
\hline $\begin{array}{l}\text { Age (years) } \\
\mathrm{X} \pm \mathrm{SD} \\
\text { Range }\end{array}$ & $\begin{array}{c}50.54 \pm 16.03 \\
18-80 \\
\end{array}$ & $\begin{array}{c}56.78 \pm 11.12 \\
33-73 \\
\end{array}$ & $\begin{array}{c}\mathrm{t} \\
4.09 \\
\end{array}$ & $\begin{array}{c}<0.001 \\
\mathrm{HS}\end{array}$ \\
\hline $\begin{array}{l}\text { Gender } \\
\text { Male } \\
\text { Female } \\
\end{array}$ & $\begin{array}{c}94(47.7 \%) \\
103(52.3 \%)\end{array}$ & $\begin{array}{l}67(59.8 \%) \\
45(40.2 \%)\end{array}$ & $\begin{array}{c}X^{2} \\
4.19 \\
\end{array}$ & $\begin{array}{c}0.041 \\
\mathrm{~S}\end{array}$ \\
\hline $\begin{array}{l}\text { Occupation } \\
\text { Jobs with physical activity } \\
\text { Sedentary jobs }\end{array}$ & $\begin{array}{l}97(49.2 \%) \\
100(50.8 \%)\end{array}$ & $\begin{array}{l}35(31.2 \%) \\
77(68.8 \%)\end{array}$ & $\begin{array}{c}X^{2} \\
9.44\end{array}$ & $\begin{array}{l}0.002 \\
\mathrm{~S}\end{array}$ \\
\hline $\begin{array}{l}\text { Residence } \\
\text { Urban } \\
\text { Rural }\end{array}$ & $\begin{array}{c}118(59.9 \%) \\
79(40.1 \%)\end{array}$ & $\begin{array}{l}31(27.7 \%) \\
81(72.3 \%)\end{array}$ & $\begin{array}{c}X^{2} \\
29.9\end{array}$ & $\begin{array}{l}<0.001 \\
\text { HS }\end{array}$ \\
\hline $\begin{array}{l}\text { Duration of diabetes } \\
\text { (years) } X \pm S D\end{array}$ & $7.85 \pm 4.17$ & $12.90 \pm 7.01$ & $\begin{array}{c}\mathrm{U} \\
6.41\end{array}$ & $\begin{array}{c}<0.001 \\
\mathrm{HS}\end{array}$ \\
\hline $\begin{array}{l}\text { Anti-DM medications } \\
\text { Insulin } \\
\text { Oral hypoglycemic drugs } \\
\text { Both therapies } \\
\end{array}$ & $\begin{array}{c}107(54.3 \%) \\
67(34 \%) \\
23(11.7 \%) \\
\end{array}$ & $\begin{array}{l}33(29.5 \%) \\
61(54.5 \%) \\
18(16.1 \%) \\
\end{array}$ & $\begin{array}{c}X^{2} \\
17.98 \\
\end{array}$ & $\begin{array}{c}<0.001 \\
\text { HS }\end{array}$ \\
\hline $\begin{array}{l}\text { Smoking } \\
\text { No } \\
\text { Yes } \\
\end{array}$ & $\begin{array}{c}169(85.8 \%) \\
28(14.2 \%)\end{array}$ & $\begin{array}{l}46(41.1 \%) \\
66(58.9 \%)\end{array}$ & $\begin{array}{c}X^{2} \\
67.45 \\
\end{array}$ & $\begin{array}{c}<0.001 \\
\text { HS }\end{array}$ \\
\hline $\begin{array}{l}\text { Hypertension } \\
\text { No } \\
\text { Yes }\end{array}$ & $\begin{array}{l}71(36 \%) \\
126(64 \%)\end{array}$ & $\begin{array}{l}37(33 \%) \\
75(67 \%)\end{array}$ & $\begin{array}{c}X^{2} \\
0.284\end{array}$ & $\begin{array}{l}0.594 \\
\text { NS }\end{array}$ \\
\hline
\end{tabular}

Group I: Patients with no PAD, Group II: Patients with PAD, $\mathrm{t}=$ students t test, $\mathrm{X}^{2}=$ chi-square test,

$\mathrm{U}=$ Mann-Whitney test $\mathrm{p}$-value is significant if $\leq 0.05 \mathrm{x}$ : mean SD: standard deviation 
Table (1) showed that the mean age was significantly higher in PAD group than in non-PAD group ( $\mathbf{p}$ value $<\mathbf{0 . 0 0 1}$ ) and the male gender was more significant than female gender in PAD group (p value $=\mathbf{0 . 0 4 1}$ ). Moreover, patients with sedentary jobs were more prevalent than patients with jobs requiring physical activity in PAD group and the sedentary occupation was more significant in PAD group than in non-PAD group. Patients who lived in rural areas were more prevalent and significantly higher than those who lived in urban areas in PAD group. The rural residence was significantly higher in PAD group than in non-PAD group. The mean duration of DM was significantly higher and longer in PAD group than in non-PAD group (p value $<\mathbf{0 . 0 0 1}$ ). Patients who used oral hypoglycemic drugs were more prevalent and significantly higher than those who used insulin therapy in PAD group (P value $<\mathbf{0 . 0 0 1}$ ). Subjects on oral hypoglycemic drugs and both therapies were significantly higher in PAD group than in non-PAD group. The number of smokers was significantly higher than that of non-smokers in PAD group. The number of smokers was significantly higher in PAD group than in non-PAD group (p value $<\mathbf{0 . 0 0 1}$ ). There was no significant difference between the studied groups as regards hypertension ( $\mathbf{p}$ value $=\mathbf{0 . 5 9 4}$ ).

In the current study, there was no significant difference between the studied groups as regards the anthropometric measurements and the vital signs (weight, height, BMI, waist circumference, hip circumference, waist-hip ratio, systolic blood pressure, diastolic blood pressure and heart rate) $(\mathbf{p}$ value $>\mathbf{0 . 0 5})$.

Table (2): Comparison between studied groups regarding the laboratory investigations (no=309)

\begin{tabular}{|c|c|c|c|c|}
\hline & $\begin{array}{l}\text { Group I } \\
\text { No=197 }\end{array}$ & $\begin{array}{l}\text { Group II } \\
\text { No=112 }\end{array}$ & $\begin{array}{c}\text { Test of } \\
\text { significance }\end{array}$ & $P$ value \\
\hline $\begin{array}{l}\text { FBS (mg/dl) } \\
X \pm S D\end{array}$ & $164.32 \pm 5.28$ & $210.5 \pm 9.39$ & $\begin{array}{c}\mathrm{U} \\
4.58 \\
\end{array}$ & $\begin{array}{c}<0.001 \\
\text { HS }\end{array}$ \\
\hline $\begin{array}{l}\text { 2Hour PPBs (mg/dl) } \\
\mathrm{X} \pm \mathrm{SD}\end{array}$ & $208.65 \pm 8.36$ & $286.39 \pm 15.82$ & $\begin{array}{c}\mathrm{U} \\
6.46 \\
\end{array}$ & $\begin{array}{c}<0.001 \\
\mathrm{HS} \\
\end{array}$ \\
\hline $\begin{array}{l}\operatorname{HbA1C}(\%) \\
X \pm S D\end{array}$ & $7.73 \pm 1.66$ & $8.79 \pm 2.10$ & $\begin{array}{c}\mathrm{t} \\
3.88 \\
\end{array}$ & $\begin{array}{c}<0.001 \\
\mathrm{HS} \\
\end{array}$ \\
\hline $\begin{array}{l}\begin{array}{l}\text { Total Cholesterol } \\
(\mathrm{mg} / \mathrm{dl}) \mathrm{X} \pm \mathrm{SD}\end{array} \\
\end{array}$ & $156.5 \pm 8.67$ & $203.94 \pm 4.39$ & $\begin{array}{c}\mathrm{t} \\
8.83 \\
\end{array}$ & $\begin{array}{c}<0.001 \\
\mathrm{HS}\end{array}$ \\
\hline $\begin{array}{l}\text { Triglycerides (mg/dl) } \\
\mathrm{X} \pm \mathrm{SD}\end{array}$ & $150.39 \pm 6.75$ & $194.62 \pm 17.06$ & $\begin{array}{c}\mathrm{U} \\
3.75\end{array}$ & $\begin{array}{c}<0.001 \\
\mathrm{HS}\end{array}$ \\
\hline $\begin{array}{l}\text { LDL (mg/dl) } \\
\mathrm{X} \pm \mathrm{SD}\end{array}$ & $86.71 \pm 8.97$ & $126.57 \pm 6.59$ & $\begin{array}{c}\mathrm{U} \\
7.21 \\
\end{array}$ & $\begin{array}{c}<0.001 \\
\mathrm{HS}\end{array}$ \\
\hline $\begin{array}{l}\text { HDL (mg/dl) } \\
\mathrm{X} \pm \mathrm{SD}\end{array}$ & $41.13 \pm 2.01$ & $40.93 \pm 1.06$ & $\begin{array}{c}\mathrm{t} \\
0.148 \\
\end{array}$ & $\begin{array}{l}0.889 \\
\text { NS }\end{array}$ \\
\hline $\begin{array}{l}\text { TLC }\left(10^{\wedge} 3 / \mathbf{m m}^{\wedge} 3\right) \\
\mathrm{X} \pm \mathrm{SD}\end{array}$ & $7.96 \pm 1.64$ & $9.55 \pm 2.86$ & $\begin{array}{c}\mathrm{U} \\
4.53 \\
\end{array}$ & $\begin{array}{c}<0.001 \\
\mathrm{HS} \\
\end{array}$ \\
\hline $\begin{array}{l}\text { Albumin creatinine } \\
\text { ratio (mg/gm) } \\
\mathrm{X} \pm \mathrm{SD} \\
\end{array}$ & $0.408 \pm 0.02$ & $0.528 \pm 0.031$ & $\begin{array}{c}\mathrm{U} \\
1.64 \\
\end{array}$ & $\begin{array}{l}1.00 \\
\mathrm{NS}\end{array}$ \\
\hline
\end{tabular}

TLC: total leucocytic count FBS: fasting blood glucose PPBS: postprandial blood glucose HbA1c: glycated hemoglobin LDL: low density lipoprotein HDL: high-density lipoprotein

Table (2) showed that among studied groups, the mean fasting blood glucose level was significantly higher in PAD group than in non-PAD group (p value $<\mathbf{0 . 0 0 1}$ ). The mean postprandial blood glucose level was significantly higher in PAD group than in non-PAD group (p value $<\mathbf{0 . 0 0 1}$ ). The mean HbA1c level was significantly higher in $\mathrm{PAD}$ group than in non-PAD group (p value $<\mathbf{0 . 0 0 1}$ ). The mean of serum total cholesterol level was significantly higher in PAD group than in non-PAD group (p value $<\mathbf{0 . 0 0 1})$. The mean of serum triglycerides level was significantly higher in PAD group than in non-PAD group (p value $<\mathbf{0 . 0 0 1}$ ). The mean $L D L$ level was significantly higher in PAD group than in non-PAD group (P value $<\mathbf{0 . 0 0 1})$. There was no significant difference between studied groups regarding HDL level (p value $\mathbf{0 . 8 8 9}$ ). The mean of serum total leucocytic count was significantly higher in PAD group than in non-PAD group (p value $<\mathbf{0 . 0 0 1}$ ). There was no significant difference between studied groups regarding urinary albumin/creatinine ratio $(\mathbf{p}$ value $=\mathbf{1 . 0 0})$ 
Table (3): Pearson correlation between ABI value and demographic, clinical, and laboratory data in all studied patients $($ no $=309)$

\begin{tabular}{|l|c|c|}
\hline \multirow{2}{*}{} & \multicolumn{2}{|c|}{ ABI value } \\
\cline { 2 - 3 } & r & P value \\
\hline Age (years) & -0.114 & 0.045 \\
\hline Duration of diabetes (years) & -0.276 & $<0.001$ \\
\hline Fasting blood sugar (FBS) (mg/dl) & -0.232 & $<0.001$ \\
\hline $\begin{array}{l}\text { 2 Hour postprandial blood glucose (PPBS) } \\
\text { (mg/dl) }\end{array}$ & -0.300 & $<0.001$ \\
\hline HBA1C (\%) & -0.259 & $<0.001$ \\
\hline Total Cholesterol (mg/dl) & -0.350 & $<0.001$ \\
\hline Triglycerides (mg/dl) & -0.208 & $<0.001$ \\
\hline LDL (mg/dl) & -0.328 & $<0.001$ \\
\hline $\begin{array}{l}\text { Albumin-creatinine ratio } \\
\text { (mg/gm) }\end{array}$ & -0.142 & 0.012 \\
\hline
\end{tabular}

ABI value was correlated negatively with age, DM duration, fasting blood glucose, postprandial blood glucose, $\mathrm{HbA1c}$, total cholesterol level, triglycerides, LDL and Albumin-creatinine ratio.

Table 4: predictors for peripheral arterial disease using Binary Logistic Regression

\begin{tabular}{|c|c|c|c|c|c|}
\hline & \multirow[t]{2}{*}{ Wald. } & \multirow{2}{*}{ significance } & \multirow{2}{*}{ B (OR) } & \multicolumn{2}{|c|}{$95 \%$ confidence interval } \\
\hline & & & & $\begin{array}{l}\text { Lower } \\
\text { bound }\end{array}$ & $\begin{array}{l}\text { Upper } \\
\text { bound }\end{array}$ \\
\hline Age & 13.18 & $<0.001 *$ & 0.889 & 0.835 & 0.947 \\
\hline Sex & 9.32 & $0.002 *$ & 32.23 & 3.46 & 229 \\
\hline Occupation & 9.22 & $0.002 *$ & 4.84 & 1.78 & 13.15 \\
\hline Residence & 0.220 & 0.630 & 0.986 & 0.980 & 1.04 \\
\hline Duration of DM & 6.46 & $0.011^{*}$ & 1.005 & 1.001 & 1.009 \\
\hline Smoking & 21.39 & $<0.001 *$ & 251.9 & 24.19 & 262 \\
\hline TLC & 10.7 & $0.001 *$ & 1.23 & 1.09 & 1.40 \\
\hline FBS & 2.68 & 0.101 & 1.01 & 0.997 & 1.01 \\
\hline $2 \mathrm{hr}$ PPBS & 0.955 & 0.328 & 1.01 & 0.997 & 1.01 \\
\hline HBA1C & 3.99 & $0.046 *$ & 0.734 & 0.543 & 0.994 \\
\hline Cholesterol & 0.088 & 0.766 & 0.996 & 0.971 & 1.02 \\
\hline Triglycerides & 2.66 & 0.103 & 1.01 & 0.999 & 1.01 \\
\hline LDL & 2.01 & 0.155 & 1.02 & 0.992 & 1.05 \\
\hline
\end{tabular}

OR: Odds ratio *=significant $\mathrm{P}$ value

This table revealed that residence, fasting blood glucose, $2 \mathrm{hr}$ post prandial blood glucose, cholesterol, triglycerides and LDL were not significantly related to the risk for developing peripheral arterial disease in asymptomatic diabetic patients $(\mathbf{P}$ - value $>\mathbf{0 . 0 5})$ :

The risk factors for developing peripheral arterial disease in asymptomatic diabetic patients were advancing age (P value <0.001) (OR 0.889), male sex (thirty-two times) $(\mathbf{P}$ value $=0.002)($ OR 32.23 $)$, sedentary life style (four times) $(\mathbf{P}$ value $=\mathbf{0 . 0 0 2})(\mathbf{O R}$ 4.84), long duration of diabetes mellitus $>12$ years $(\mathbf{P}$ value $=0.011)($ OR1.005), smoking $(P$ value $<0.001)$ (OR 251.9) and uncontrolled hyperglycemia (high HBA $1 \mathrm{C}>8.5 \%)(\mathrm{P}$ value $=\mathbf{0 . 0 4 6})($ OR 0.734 $)$.

PAD was associated with elevated TLC (P value $=0.001)($ OR 1.23).

\section{DISCUSSION}

The current study found a high prevalence of PAD in asymptomatic diabetic patients selected from Menoufia University hospitals (36.2\%). This study is close to Shaikh et al. ${ }^{\left({ }^{9}\right)}$ who showed a high prevalence of PAD among diabetic patients without any symptoms for PAD (34.8\%). In addition, this study was close to Aljarid et al. ${ }^{(10)}$ who showed a high prevalence of PAD in diabetic patients with or without symptoms for PAD (32.2\%).

Many studies showed the prevalence and the risk factors for developing PAD in diabetic patients without any symptoms for PAD such as Shaikh et al. ${ }^{(9)}$ and Ghosh et al. ${ }^{\left({ }^{(11)}\right.}$. However, other studies showed the prevalence and the risk factors for developing PAD in diabetic patients with or without symptoms for PAD.

This study showed that the mean age was significantly higher in PAD group than in non-PAD 
group. This agrees with Aljarid et al. ${ }^{(10)}$, Ghosh et al. (11) and Weledji et al. ${ }^{(12)}$ who showed that increasing age was a significant risk factor for PAD in diabetic patients. Against this study, Agboghoroma et al. ${ }^{(13)}$ showed that there was no significant difference between the two groups regarding age.

This study showed that the male sex was more predominant than female sex in diabetic patients with PAD may be because the majority of our participants were males and smokers. This agrees with Shaikh $\boldsymbol{e t}$ al. (9) and Ghosh et al. ${ }^{(11)}$ who showed that there was male predominance in asymptomatic diabetic patients with PAD. Against this study, Agboghoroma et al. ${ }^{(13)}$ showed that there was female predominance due to associated high BMI and total cholesterol levels. Furthermore, Weledji et al. ${ }^{(12)}$ showed that there was no significant difference between both groups regarding gender.

The current study showed that patients with sedentary jobs were more predominant in PAD group than in non-PAD group. This agrees with Felício et al. (14) who showed that sedentary lifestyle was an important risk factor for PAD. Against this study, Weledji et al. ${ }^{(12)}$ showed that there was no significant difference between studied groups regarding occupation.

The current study showed that the prevalence of PAD in patients from rural residence was significantly higher than in those from urban residence due to the low socioeconomic and educational level. This study agrees with Weledji et al. ${ }^{(12)}$ who showed that the prevalence of PAD was high in tropical forests. In contrary, Weragoda et al. (15) showed that no significant difference between both groups regarding the residence.

This study showed that the mean duration of DM was significantly higher in PAD group than in nonPAD group. This study agrees with Ghosh et al. ${ }^{(11)}$ who showed that the long DM duration was a risk for PAD in diabetic patients without any symptoms for PAD. In addition, it agrees with Felício et al. ${ }^{(14)}$ regarding that the duration of DM was a risk for PAD in diabetic patients with or without symptoms for PAD. In contrary, Shaikh et al. ${ }^{(9)}$ and Agboghoroma et al. ${ }^{(13)}$ showed that no significant difference between both groups regarding DM duration.

This study showed that patients on oral hypoglycemic drugs and those on both therapies were more predominant in PAD group than non-PAD group. In addition, the prevalence of PAD was significantly higher in patients on oral hypoglycemic drugs than in insulin users due to the majority of participants used 2 or 3 oral hypoglycemic drugs or mixed therapy and were not compliant. This study agrees with Yang $\boldsymbol{e t}$ al. (16) who showed that PAD was significantly higher in patients on oral hypoglycemic drugs than in insulin users. In contrary, Yeboah et al. ${ }^{(17)}$ showed that PAD was more frequent in insulin users due to the effect of insulin resistance on atherosclerosis progression. Besides, Aljarid et al. ${ }^{(10)}$ showed that no significant difference between both groups regarding anti-DM medications.

The current study showed that the number of smokers was significantly higher in PAD group than in non-PAD group. So, smoking was a risk factor for PAD. Smoking led to atherosclerosis, which is the main cause for PAD by damaging the blood vessels through raising the blood pressure and unhealthy cholesterol levels. Furthermore, nicotine in tobacco also tightens the blood vessels and reduces the blood flow in the arteries. This study agrees with Shaikh et $\boldsymbol{a l}$. $^{(9)}$ and Shou et al. ${ }^{(18)}$ who showed that smoking was a risk for PAD in diabetic patients. In contrary, Aljarid et al. ${ }^{(10)}$ showed that no significant difference between both groups regarding smoking.

This study showed that there was no significant difference between both groups regarding hypertension may be because the majority were wellcontrolled by anti-hypertensive drugs. This study agrees with Agboghoroma et al. ${ }^{(13)}$ who showed that there was no significant difference between studied groups regarding hypertension. Against this study, Ghosh et al. (11) and Shou et al. (18) showed that hypertension was a significant risk factor for PAD in diabetics because elevated blood pressure leads to hardening of the blood vessels, which is known as atherosclerosis that results in development of PAD.

This study showed that there was no significant difference between both groups regarding all-anthropometric measurements and this might be due to the effect of obesity paradox phenomenon demonstrated by variable studies. Ludhwani $\boldsymbol{e t}$ al. ${ }^{(\mathbf{1 9})}$ showed that in spite of the strong association between elevated BMI, cardiovascular outcomes and PAD, there were favorable cardiovascular outcomes in obese patients as compared to those with normal BMI, which was known as the obesity paradox. This had been explained by different theories such as body composition of large muscle bulk, improved cardiorespiratory fitness, greater mobilization of endothelial progenitor cells, decreased thromboxane production, increased ghrelin sensitivity and excess adipose tissue produced of soluble tumor necrosis factor receptor, which plays a protective role by neutralizing the toxic effects of tumor necrosis factor alpha. Similar paradoxical results were observed in patients with peripheral arterial disease (PAD). PAD was noted in the underweight patients. However, this was attributed to excess mortality in the underweight who had a history of smoking and obstructive lung disease. the current study agrees with Ana Tereza do Nascimento et al. ${ }^{(20)}$ regarding all-anthropometric measurements, with Shaikh et al. ${ }^{(9)}$ and Shou et al. ${ }^{(18)}$ regarding BMI and with Weragoda et al. ${ }^{(15)}$ regarding waist circumference 
and waist hip ratio. In contrary, Agboghoroma et al. ${ }^{(13)}$ showed that the higher BMI and the higher waist circumference were risk factors for PAD.

The current study showed that poor glycemic control was a risk for PAD because of progression of atherosclerosis process by abnormal platelets activation, enhanced production of advanced glycation end- products and the oxidative stress. The means of FBS, 2 hrPPBS and HBA1c were significantly higher in PAD group than in non-PAD group. This study agrees with Shaikh et al. ${ }^{(9)}$ and Yang et al. (16) regarding that FBS and HBA1c levels were higher in patients with PAD. In contrast, Cornejo Del Río et al. (21) showed no significant difference between studied groups regarding FBS and 2 hrPPBS. Moreover, Shou et al. (18) reported that there was no significant difference regarding $\mathrm{HBA} 1 \mathrm{c} \%$.

The current study showed that dyslipidemia was a risk for PAD in diabetic patients because of increasing atherosclerosis and its related oxidative stress. The means of total cholesterol, triglycerides and LDL levels were significantly higher in PAD group than in non-PAD group and this agrees with Soyoye $\boldsymbol{e t}$ al. ${ }^{(5)}$ who demonstrated that dyslipidemia was a risk factor for PAD. In contrast, Cornejo Del Río et al. ${ }^{\text {(21) }}$ showed no significant difference between studied groups regarding dyslipidemia. However, our study showed no significant difference between both groups regarding HDL level and this agrees with Cornejo Del Río et al. ${ }^{(21)}$ but against Agboghoroma et al. ${ }^{(13)}$ who showed that low serum HDL level was a risk factor for PAD. Ghosh et al. ${ }^{(11)}$ agrees with our study considering that serum HDL was of non-significant difference between both groups. In contrast to the current study, Ghosh et al. (11) showed non-significant difference between both groups as regards serum total cholesterol and LDL.

This study showed high total leucocytic count in PAD group as a sequalae to PAD due to the association between atherosclerosis and rising of inflammatory markers. This agrees with Soyoye $\boldsymbol{e t}$ al. (5) regarding leucocytic count.

Our study showed that there was no significant difference between both groups regarding albuminuria. This agrees with Yang et al. ${ }^{(16)}$ but in contrary to Weledji et al. ${ }^{(12)}$ who showed that proteinuria was a significant association with PAD.

\section{CONCLUSION AND RECOMMENDATIONS}

Prevalence of PAD in asymptomatic diabetic patients was $36.2 \%$. Advancing age, sedentary life style, smoking, dyslipidemia, long duration of DM and poor glycemic control were the risk factors for PAD. However, hypertension and obesity were not significant in our study. ABI screening must be mandatory in all diabetic patients even if not symptomatic for early diagnosis of PAD and enhancing its outcome.
Financial support and sponsorship: Nil. Conflicts of interest: Nil.

Declaration: This manuscript has not been published or submitted for publication elsewhere.

Acknowledgment: All authors have contributed significantly and agreed with the content of the manuscript.

\section{REFERENCES}

1. International Diabetes Federation (2019): IDF Diabetes Atlas, 9th edn. Brussels, Belgium: 2019. Available at: https://www.diabetesatlas.org.

2. World Health Organization (2016): Global Report on Diabetes. Geneva, 2016. https://apps.who.int/iris/bitstream/handle/10665/ 204871/ 9789241565257_eng .pdf;jsessionid=E05BB16F0916D8D2B81AF59D8A7F CB69? sequence $=1$

3. Koon K (2019): Overview of peripheral arterial diseaseheart and blood vessel disorders. Merck Manuals Consumer Version.

https://www.msdmanuals.com/home/heart-and-bloodvessel-disorders/peripheral-arterial-disease/overviewof-peripheral-arterial-disease

4. Arora E, Maiya A, Devasia T et al. (2019): Prevalence of peripheral arterial disease among type 2 diabetes mellitus in coastal Karnataka. Diabetes and Metabolic Syndrome: Clinical Research and Reviews, 13 (2): 1251-1253.

5. Soyoye D, Ikem R, Kolawole B et al. (2016): Prevalence and correlates of peripheral arterial disease in Nigerians with type 2 diabetes. https://www.hindawi.com/journals/amed/2016/3529419 /

6. Shukla V, Fatima J, Ali M et al. (2018): A study of prevalence of peripheral arterial disease in type 2 diabetes mellitus patients in a teaching hospital. The Journal of the Association of Physicians of India, 66 (5): 57-60.

7. Hur K, Jun J, Choi Y et al. (2018): Color doppler ultrasonography is a useful tool for diagnosis of peripheral artery disease in type 2 diabetes mellitus patients with ankle-brachial index 0.91 to 1.40 . Diabetes and Metabolism Journal, 42 (1): 63-73.

8. Rooke T, Hirsch A, Misra S et al. (2011): 2011 ACCF/AHA Focused Update of the Guideline for the Management of Patients With Peripheral Artery Disease (updating the 2005 guideline): a report of the American College of Cardiology Foundation/American Heart Association Task Force on Practice Guidelines. Journal of the American College of Cardiology, 58 (19): 2020 45.

9. Shaikh S, Ali M, Saifullah S (2020). Risk Factors for Asymptomatic Peripheral Artery Disease in Type II Diabetes Mellitus Patients, a Cross-Sectional Study at Tertiary care Hospital. Journal of Advances in Medicine and Medical Research, 32 (23): 148-155.

10. Aljarid J, Alazmi A, Almaeen A et al. (2018): Prevalence and Pattern of Peripheral Arterial Disease among Diabetic Individual in Al-jouf Region. 
Department of Family and Community Medicine, Aljouf University. The Egyptian Journal of Hospital Medicine, 73 (5): 6641-6645.

11. Ghosh U, Datta S, Banerjee S (2011): Asymptomatic peripheral arterial disease in type 2 diabetes mellitus: prevalence patterns and risk factor associations. Int $\mathbf{J}$ Diabetes Dev Ctries, 31: 229-238.

12. Weledji E, Alemnju N, Nouediou C (2018): The use of ankle brachial pressure indices in a cohort of black African diabetic patients. Ann Med Surg (Lond), 19: 35:20-24.

13. Agboghoroma O, Akemokwe F, Puepet F (2020): Peripheral arterial disease and its correlates in patients with type 2 diabetes mellitus in a teaching hospital in northern Nigeria: a cross-sectional study. BMC Cardiovasc Disord., 20 (1): 102-7.

14. Felício J, Koury C, Abdallah Zahalan N et al. (2019): Ankle-brachial index and peripheral arterial disease: An evaluation including a type 2 diabetes mellitus drugnaïve patients cohort. Diab Vasc Dis Res., 16 (4): 344350 .

15. Weragoda J, Seneviratne R, Weerasinghe $M$ et al. (2016): Risk factors of peripheral arterial disease: a case control study in Sri Lanka. BMC Res Notes, 9 (1): 50813.

16. Yang C, Lin C, Li C et al. (2020): Fasting plasma glucose variability and $\mathrm{HbA1c}$ are associated with peripheral artery disease risk in type 2 diabetes. Cardiovasc Diabetol., 19 (1): 4-10.

17. Yeboah K, Puplampu P, Yorke E et al. (2016): Body composition and ankle-brachial index in Ghanaians with asymptomatic peripheral arterial disease in a tertiary hospital. BMC Obes., 3: 27-32.

18. Shou Z, Zhao Y, Zhang Y et al. (2020): Risk factors for peripheral arterial disease in elderly patients with Type2 diabetes mellitus: A clinical study. Pak J Med Sci., 36 (6): 1344-1348.

19. Ludhwani D, Wu J (2019): Obesity Paradox in Peripheral Arterial Disease: Results of a Propensity Match Analysis from the National Inpatient Sample. Cureus., 11 (5): 4704.

20. Sales AT de N, Fregonezi GA de F, Silva A et al. (2015): Identification of peripheral arterial disease in diabetic patients and its association with quality of life, physical activity and body composition. J Vasc Bras., 14: 46-54.

21. Cornejo Del Río V, Mostaza J, Lahoz C et al. (2017): Prevalence of peripheral artery disease (PAD) and factors associated: An epidemiological analysis from the population-based Screening PRE-diabetes and type 2 diabetes (SPREDIA-2) study. PLoS One, 12 (10): e0186220. 